\title{
LA PROSA SEMI-ABSTRACTA DE HAROLDO DE CAMPOS. UNA APROXIMACIÓN A LOS TEXTOS TARDÍOS DE GALÁXIAS ${ }^{1}$
}

http://dx.doi.org/10.11606/issn.2237-1184.v0i29p86-104

Jorge Manzi Cembrano

Universidade de São Paulo (USP)

\section{RESUMO}

En la primera parte de este escrito presento una aproximación a Galáxias de Haroldo de Campos como un proyecto en prosa que explora nuevas posibilidades en un campo artístico paradojal, surgido en los años 60 , que he denominado semi-abstracto. Sin renunciar a principios básicos del arte abstracto, esta nueva prosa se orientaría hacia la vida cotidiana retomando principios figurativos. En la segunda parte, trabajando dentro de este marco histórico-artístico, he analizado dos pasajes de Galáxias con el propósito de elaborar el sentido de crisis que los textos tardíos de esta obra pueden provocar.

\section{ABSTRACT}

In the first part of this text I present an approach to Haroldo de Campos' Galáxias as a prose project that probes for new possibilities in a paradoxical artistic field, emerged in the 60s, which I have called the semi-abstract. While maintaining principles basic to abstract art, this new prose orients itself towards everyday life returning to figurative principles. In the second part, working within this art-historical frame, I have analyzed two passages of Galáxias aiming to elaborate the sense of crisis that the late texts of this work can provoke.

\section{PALAVRAS-CHAVE:}

Prosa semi-abstracta; Galáxias;

Haroldo de Campos; estéticas constructivistas; estudios pos-1945.

\section{KEYWORDS}

Semi-abstract prose;

Galáxias;

Haroldo de Campos; constructivist aesthetics; post-1945 studies.

\footnotetext{
${ }^{1}$ La escritura de este texto contó con el apoyo de Becas Chile, Becas de Doctorado en el Extranjero. Para una versión más elaborada y extendida de las ideas y juicios ensayados por primera vez aquí, ver MANZI CEMBRANO, Jorge. Abstração e informalismo depois de 1945: de Pedrosa e Greenberg à nova prosa de Haroldo de Campos. Tesis de doctorado en Teoría Literaria, Departamento de Teoria Literária e Literatura Comparada da Faculdade de Filosofia, Letras e Ciências Humanas da Universidade de São Paulo, 2019, capítulos 6 y 7.
} 


\section{Una prosa semi-abstracta}

En lo que refiere a Galáxias, la nueva prosa que Haroldo de Campos comenzó a escribir en torno a 1964, todo parece conducirnos a problemas de concepción. Concepción de una forma posible o viable en situación de crisis. Durante el tiempo en que he estado estudiando los 50 textos que componen esta obra, no ha dejado de incomodarme, en diferentes momentos, la misma pregunta: ¿estaré aproximándome a ellos desde un ángulo adecuado? Al respecto, un close reading de los textos ha sido fundamental. Sin embargo, por sí mismo nunca resolvió el problema referido al ángulo de aproximación. Aprender a tomar distancia de la superficie condensada y difícil de estos textos, y reflexionar respecto a lo que estaría en juego en ellos, en términos formales, pero también históricoartísticos, se tornó el ejercicio clave y, a mi juicio, el más interesante del estudio. Pues esta nueva prosa, aun en sus momentos menos convincentes, nos presiona a repensar categorías, a ajustar el tipo de preguntas que valdría la pena realizar, e, incluso, a preguntarnos si no estaríamos, en definitiva, frente a un nuevo modo simbólico.

Al leer Galáxias el crítico no pisa terreno firme. En principio, no cuenta con modelos previos, es decir, un conjunto de obras del mismo género (p.e. novela, cuento, poema lírico) o una tradición teórica que haya establecido un repertorio de problemas y supuestos capaces de enmarcar nuestra lectura. No contamos con una teoría de este tipo de prosa como contamos con una teoría de la novela, de la poesía lírica o de la poesía épica. Sin un marco común, no sorprende que no haya consenso dentro de la fortuna crítica de Galáxias respecto al género o tradición en la que sería posible inscribirla. La obra pareciera mantener la existencia solitaria e incómoda de un ornitorrinco literario; sin términos de comparación en el campo literario que le fue contemporáneo.

La fortuna crítica de Galáxias ha estado fijada al ejercicio de asignarle un género reconocido, intentando estabilizar algún ángulo de aproximación, sea afirmando su esencia poético-lírica, o bien, su esencia épico-narrativa. Este ejercicio, creo, ha dificultado el acceso a aspectos relevantes de la forma, así como a una comprensión más precisa del proyecto original. El propio autor no escapó a estas ansiedades al declarar, retrospectivamente, que, si bien la obra habría respondido en sus inicios a 
una "insinuación épica", se habría "resuelto" en una "epifánica", queriendo decir con eso, en poesía. ${ }^{2}$ Críticos como Gonzalo Aguilar (2005; 2015) y Marcos Siscar (2010), en sintonía con esta línea, han concebido la obra como un poema, aproximándose a ella a partir de los términos y principios de la poética de Mallarmé. ${ }^{3}$ En la línea opuesta, Luiz Costa Lima (1989) ha insistido en su forma prosística y prosaica, inscribiéndola en la tradición épica e impura de Joyce (Rabelais y Homero), distanciándola polémicamente del lado de Mallarmé. 4 Tanto en una línea como en la otra, los críticos parecen presionados por posicionarse entre lírica o épica, y, adicionalmente, por fundamentar su lectura afirmando la primacía de algún maestro del paideuma de la poesía concreta (Mallarmé o Joyce).

Una tercera vía, menos fijada a la oposición tradicional entre épica y lírica, y a las ansiedades por resolverla, ha sido la de Marjorie Perloff (2001; 2012). Pionera en el estudio de nuevos modos de prosa publicados en los años 60 y 70 por autores como John Ashbery, Robert Creeley, John Cage, David Antin y Samuel Beckett, la crítica estadunidense se ha interesado en más de una ocasión por Galáxias. Según Perloff, se trataría de una "prosa concreta" que, por sus ritmos de repetición y sus rimas obsesivas, sería heredera de la prosa cubista de Gertrude Stein. ${ }^{5}$ En otra ocasión, agregó que estaría más cerca del cubismo ideográmico y prosaico de Ezra Pound que del espaciamiento ideográfico de Mallarmé. ${ }^{6}$ No obstante, de acuerdo a Perloff, la potencia de Galáxias radicaría menos en sus afiliaciones con el pasado literario que con las vías que podría abrir para la prosa literaria contemporánea: “Una serie de 'monólogos exteriores' en prosa, así Galáxias apuntaría el camino desde la 'prosa' de modernistas como Joyce y Stein hacia la nueva poesía en prosa de la última parte del siglo $X X^{\prime \prime} .7$ Pese a que

\footnotetext{
2 Me refiero a la conocida declaración realizada por Haroldo de Campos en los 80: “hoje, retrospectivamente, eu tenderia a vê-lo [a Galáxias, JMC] como uma insinuação épica que se resolveu numa epifânica" (CAMPOS, Haroldo de. Galáxias. São Paulo: Editora Ex Libris, 1984, s.p.).

${ }^{3}$ Cf. AGUILAR, Gonzalo. "Haroldo de Campos: a transpoética" In: Idem. Poesia concreta brasileira. As vanguardas na encruzilhada modernista. São Paulo: Edusp, 2005; "Parte III. A vereda para o branco". In: Ibidem. Hélio Oiticica, a asa branca do êxtase. Arte brasileira 1964-1980. Rio de Janeiro: Anfiteatro, 2015; SISCAR, Marcos. "Estrelas extremas: sobre a poesia de Haroldo de Campos". In: Ibidem. Poesia e crise. Ensaios sobre a 'crise da poesia' como topos da modernidade. São Paulo: Editora Unicamp, 2010.

${ }^{4}$ Cf. COSTA LIMA, Luiz. "Capítulo VI: Arabescos de um arabista: Galáxias de Haroldo de Campos." In: A aguarrás do tempo. Estudos sobre a narrativa. Rio de Janeiro: Rocco, 1989.

${ }^{5}$ Cf. PERLOFF, Marjorie. "'Concrete Prose' in the Nineties: Haroldo de Campos's Galaxies and After". Contemporary Literature. 42 (2), pp. 270-93, 2001.

${ }^{6}$ Cf. PERLOFF, Marjorie, "Refiguring the Poundian Ideogram: From Blanco/Branco to the Galaxias". Modernist Cultures. 7 (1), p. 40-55, 2012.

${ }^{7}$ PERLOFF, Marjorie. "'Concrete Prose' in the Nineties: Haroldo de Campos's Galaxies and After", op.cit., p.283. Cita original: "A series of 'exterior monologues' in prose, Galáxias points the way from the 'prose' of modernists like Joyce and Stein to the new prose poetry of the late twentieth century". El término "poesía en prosa", sin embargo, puede conducir a equívocos. Perloff aclara que con ello quiere referir a "'textos límites' (...) que, como Galáxias, desafían la distinción entre
} 
su comentario se ha limitado a pocos textos de la obra, y no alcanza una lucidez y precisión formal comparable a la de sus estudios sobre Ashbery, Antin o Beckett, tiene para nosotros el valor programático de inscribir Galáxias en el campo de una nueva prosa que, a partir de los años 60, sedujo a artistas talentosos e innovadores formados en el rigor de las estéticas constructivo-modernistas del período pos-1945. Así, siguiendo esta pista, se torna posible defender una tercera vía en la fortuna crítica, según la cual esta obra participaría, junto a la de otros autores de su generación, de un modo novedoso de prosa literaria que se abre hacia el período contemporáneo. ${ }^{8}$

Para elaborar con más precisión esta tercera vía, centrada en una reflexión sobre las singularidades de una nueva prosa, creo necesario retomar algunos elementos del contexto histórico-artístico específico en el que Haroldo de Campos concibió Galáxias como proyecto. Esto nos permitirá definir un campo artístico en el que una tensión estética entre abstracción y figuración se torna central, relegando a un segundo plano la tensión más tradicional entre épico y lírico que ha dominado en la fortuna crítica de la obra. Se trata de un campo o régimen que llamaré semiabstracto.

En los años 60, destacados artistas formados en el movimiento abstracto del período pos-1945, sea en su variante geométrica o informalista, se rebelaron contra su regla básica, anti-figurativa o antiilusionista, que exigía componer exclusivamente en base a las cualidades

\footnotetext{
poesía y prosa y enfatizan la materialidad del texto" (Idem., pp.283-284, traducción mía). Es decir, Perloff ha evitado inscribir Galáxias de modo unilateral en la tradición de la poesía. Cita original: “'limit texts' (...) that, like the Galaxies, challenge the distinction between poetry and prose and emphasize the materiality of the text"

8 Había afirmado que no contamos con una teoría de esta nueva prosa como contamos con una teoría de la novela o de la poesía lírica. Sin embargo, a partir de los 80 , esfuerzos de carácter más sistemático, orientados a dar base a tal teoría, han sido realizados por críticos como Perloff y Stephen Fredman. Ambos críticos percibieron que, a partir de los 60, un número importante de artistas de vanguardia eligieron la prosa literaria para proyectos artísticos que no encajaban en géneros como la poesía lírica o épica, la novela o el cuento. En lengua inglesa destacan casos como Three poems (1972) de Ashbery; Mabel: A story (1976) de Creeley; How it is (1961/1964) y Fizzles (1976) de Beckett; algunos textos de Cage en Silence (1961) y su Diary: How to improve the world (1968); Talking (1972) y Talking at the Bounderies (1976) de David Antin. Cf. PERLOFF, Marjorie. Poetics of indeterminacy. Rimbaud to Cage [1981]. Evanston: Northwestern University Press, 1999; Idem., The Dance of the Intellect. Studies in the Poetry of the Pound Tradition. [1985]. Evanston: Northwestern University Press, 1996; FREDMAN, S. Poet's Prose. The Crisis in American Verse. Second edition. Cambridge: Cambridge University Press, 1990. En lengua portuguesa, en este estudio propondremos Galáxias como un caso inaugural. Expandiendo nuestro arco temporal, publicaciones recientes como $O$ (2008) de Nuno Ramos sugieren que la idea de una nueva prosa inspirada en sensibilidades y concepciones constructivo-modernistas aún está vigente y es capaz de suscitar interés en públicos amplios.
} 
intrínsecas de cada medio específico (fuese pintura, música o literatura). Es decir, se rebelaron contra los límites del principio de abstracción artística que había dominado durante los 50 en países como Brasil y Estados Unidos, defendido por críticos del peso de Clement Greenberg y Mário Pedrosa. ${ }^{9}$ La rebelión se manifestó en estos países como una nueva orientación hacia el afuera cotidiano - el lugar donde habitaba el otro de la abstracción - , en una actitud que ha sido descrita por la crítica como anti-arte, pop, neosurrealista y neorrealista. ${ }^{10}$ Algunos artistas, como Hélio Oiticica o los minimalistas norteamericanos, se expandieron, literalmente, desde el marco bidimensional del cuadro hacia el espacio tridimensional de la vida cotidiana. Otros, como Haroldo de Campos en sus Galáxias, sin pretender transgredir los límites de la obra de arte, se propusieron incorporar el afuera de un modo menos literalista, recuperando recursos como el ilusionismo, la figuración y el collage.

Genéricamente, propongo llamar semi-abstracción a este retorno de lo prosaico y de la figuración después del ciclo abstracto de la segunda posguerra. Al insistir o conservar la noción de abstracción quiero indicar que la referida tendencia, iniciada en los 60, se caracterizaría menos por la intención de abolir concepciones y sensibilidades abstractas que por la voluntad de expandirla hacia zonas que habían sido excluidas durante los 50, como la figura, el ilusionismo, la imagen y la vida cotidiana. Para tornar más convincente e inteligible esta propuesta, me parece importante inscribirla en el marco de otras elaboraciones teóricas afines, y mejor conocidas. Para ello, retomaré algunas citas que considero particularmente orientadoras.

\footnotetext{
${ }^{9}$ El principio de la abstracción artística funcionó como idea regulativa básica de la teoría del modernismo de Clement Greenberg, el más influyente crítico de artes visuales de la segunda posguerra. En el contexto brasilero, este principio encontró su defensor más riguroso e influyente en Mário Pedrosa. Para ambos críticos, abstracción fue el término general que resumía la tendencia anti-ilusionista del arte moderno, que se manifestaba en una insistencia cada vez más consciente y radical a componer apenas en base a las cualidades intrínsecas de cada medio específico. Para una versión breve y esquemática de esta teoría tardía del modernismo ver GREENBERG, Clement. "Modernist Painting". In: The Collected Essays and Criticism. Volume 4. Modernism with a Vengeance. 1957-1969. Ed. John O'Brian. Chicago: The University of Chicago Press, 1993. Para la versión defendida por Pedrosa en Brasil durante los 50, ver PEDROSA, Mário. "Panorama da pintura moderna". In: Modernidade Cá e Lá. Textos Escolhidos IV (org. Otília Arantes). São Paulo: Edusp, 2000.

${ }^{10}$ En los años 60, "nuevo realismo" fue tal vez el término más usado para describir esta tendencia. Entre quienes lo emplearon destaco a Mário Schenberg, Pierre Restany y al propio Haroldo de Campos. Comentando el caso brasilero, mejor conocido como "Nova Objetividade", Otília Arantes ha enfatizado su carácter anti-arte, neo-dadá y pop. Cf. ARANTES, Otília. "Depois das vanguardas". In: Arte em revista, n. 7. São Paulo: Kairós, 1983, pp.5-24. En Estados Unidos, el grupo de críticos reunidos en torno a la revista October, ha insistido en el carácter neosurrealista y neodadaísta de movimientos como el pop art y el minimalismo. Cf. FOSTER, Hal. The return of the real. The avant-garde at the return of the century. Cambridge: The MIT Press, 1996.
} 
La primera corresponde al crítico T. J. Clark, quien en su esfuerzo por entender los impasses que Jackson Pollock enfrentó al reintroducir la figuración a su versión del arte abstracto, afirmó lo siguiente:

no existen reglas para juntar nuevamente lo figurativo y lo abstracto una vez que lo abstracto ha llegado. No hay criterios disponibles, no hay cómo apoyarse en facilismos. Estas son las circunstancias en donde las pinturas [en nuestro caso, la nueva prosa, JMC] necesitan con mayor urgencia de intérpretes, incluso de aquellos implacables. ${ }^{11}$

En su estudio, Clark ha querido destacar la especificidad de una "segunda venida de la figura", una que tuvo lugar cuando el movimiento abstracto ya se había consolidado (y comenzaba a mostrar sus límites y rigideces):

El problema era, por cierto, encontrar un modo de reconciliar esa segunda venida de la figura con un trabajo orientado a aniquilar la representación siendo realizado al mismo tiempo. La figura, si fuese a aparecer del todo, tendría que hacerlo desde o contra tal trabajo, como el estricto opuesto de él - la negación de la negación. ${ }^{12}$

Bastante antes que Clark, Clement Greenberg, al percibir a inicios de los 60 la consolidación de una segunda venida de la figura, inaugurada por artistas como Robert Rauschenberg y Jasper Johns, propuso una fórmula sugerente para definir nuestro campo semi-abstracto: llamó esta tendencia "representación sin hogar" ${ }^{13}$ Es decir, la figura e ilusión retornan, pero no a su casa, no a su contexto artístico familiar. En esta elaboración pionera, muy cercana a la de Clark, Greenberg argumentó que la fuerza de estas formas neofigurativas o neorrealistas dependería de la lucidez con la que

${ }^{11}$ CLARK, T. J. "The Unhappy Consciousness". In: Farewell to an idea. Episodes from a History of Modernism. New Haven: Yale University Press, 2014, p. 351, traducción mía. Cita original: “There are no rules for putting the figurative and abstract back together once the abstract has arrived. No available criteria, no leaning on facility. These are the circumstances when pictures most need interpreters, even ruthless ones."

${ }^{12}$ Idem, ibidem, p. 344, cursivas del autor, traducción mía. Cita original: "The problem, of course, was to find a way of reconciling that second coming of the figure with the work to annihilate likeness being done at the same time. The figure, if it was to appear at all, would have to do so out of or against that work, as the strict contrary of it - the negation of the negation". "Negación de la negación", pues a la negación de la figura y del ilusionismo realizada por el movimiento abstracto le seguiría una segunda negación, que funcionaría como el impulso básico dentro de un campo o régimen artístico semi-abstracto.

${ }^{13}$ GREENBERG, Clement. "After abstract Expressionism" [1962]. In: The Collected Essays and Criticism. Volume 4. Modernism with a Vengeance. 1957-1969. Ed. John O'Brian. Chicago: The University of Chicago Press, 1993, p. 124, traducción mía. Cita original: "homeless representation". 
el artista se mostrase capaz de elaborar o revelar una lógica contradictoria o paradojal:

Todo aquello que usualmente sirve a la representación y a la ilusión comienza a servir a nada sino a sí mismo, esto es, a la abstracción; mientras que todo aquello que usualmente sirve a lo abstracto y a lo decorativo - planaridad, meros contornos, diseño multilateral o simétrico - es puesto al servicio de la representación. Y en cuanto más explícitamente sea trabajada esta contradicción, más efectiva tenderá a ser, en todo sentido posible, la pintura. ${ }^{14}$

Así, siguiendo tanto a Clark como a Greenberg, podríamos sugerir que el campo semi-abstracto sería un régimen artístico que da lugar a formas paradojales, en las que algo parece no cuadrar. En tales formas semi-abstractas convivirían dos impulsos que se interfieren. Un impulso abstracto, centrípeto, que se volvería reflexivamente sobre el propio soporte artístico, "aniquilando" - para retomar la expresión de Clark la representación y el ilusionismo. Y un impulso figurativo, de carácter centrífugo, que apuntaría hacia el afuera, activando en el receptor, aunque sea de modo inestable o vago, alguna noción de ilusión y referencialidad basado en modelos exteriores al propio medio o soporte artístico.

Este sería, a mi juicio, el régimen o campo general, con especificidad histórico-artística, en el que un proyecto como Galáxias se torna inteligible. Un campo que nos exige, en tanto críticos, afinar un conjunto de preguntas y categorías formales para pensar en la tensión estética entre abstracción y figuración, abstracción y neorrealismo, abstracción y vida cotidiana. Dicho esto, debemos agregar que lo que aquí nos interesa, específicamente, es el caso de una prosa semi-abstracta.

En 1964, en el cuarto número de la revista Invenção, Haroldo de Campos anunció el proyecto de una "nova prosa" que, sin renunciar a principios y técnicas fundamentales del concretismo poético, se orientaría frontalmente hacia la vida cotidiana, retomando recursos como la figuración, la ficción, el collage y el discurso narrativo. ${ }^{15}$ Anunciaba, de este modo, una combinación singular de principios constructivistas y principios figurativos puestos al servicio de un posible "novo realismo". 16 El resultado fueron 50 textos en prosa, enmarcados estrictamente por los

\footnotetext{
14 Idem, ibidem, p. 127, traducción mía. Cita original: "Everything that usually serves representation and illusion is left to serve nothing but itself, that is, abstraction; while everything that usually serves the abstract and decorative - flatness, bare outlines, all-over or symmetrical design - is put to the service of representation. And the more explicit this contradiction is made, the more effective in every sense the picture tends to be"

${ }^{15}$ Cf. CAMPOS, Haroldo de. "dois dedos de prosa sobre uma nova prosa". In: Invenção, n. 4. São Paulo: Obelisco, dez. 1964, p. 112.

${ }^{16}$ Idem, ibidem, ibidem.
} 
límites de una hoja en blanco, o, en términos constructivistas, por un plano. Los primeros 25 textos, escritos entre 1963 y 1966, fueron publicados durante la década de 60 en el cuarto y quinto número de Invenção. Los 25 restantes, que aquí llamaremos textos tardíos, fueron escritos entre 1966 y 1976. Sólo aparecerían en su totalidad en la edición definitiva de Galáxias de $1984 .{ }^{17}$

\section{El sentido de crisis en los textos tardíos de Galáxias}

pulverulenda que eu linho e desalinho que eu cardo e descarto e descardo e carto e corto e discordo e outra vez recarto recorto reparto e disposto o baralho está farto está feito e almaço este fólio que eu passo como o jogo que espaço hier offnen with care breakable attention très fragile attenzione vorsicht molto fragile leicht zervrechlich pena que ela seja uma ptyx she's a whore as paredes de kirchberger forradas de mulheres peladas panóplia de pentelhos e se tomava chá e se discutia sobre culinária torradas com geleia de cereja civilizada atmosfera britânica made in stuttgart pena que ela seja a cadeira sacudida de riso espernava grossas coxas de nylon e ives klein pintava com mulheres desnudas manchas borrachosas de azul carimbando o vazio da tela ${ }^{18}$

La prosa semi-abstracta de Haroldo de Campos emplea técnicas constructivistas como el montaje, la repetición y operaciones aleatorias, en paralelo a modos discursivos como la narración y el comentario. Considero que estas técnicas y recursos se organizan bajo el principio más general de un contrapunto entre concreción y comentario. En el primero modo, la concreción, el autor intensificaría el uso de técnicas constructivistas, insistiendo en una noción simultaneísta del tiempo y en una noción multilateral de espacio. Se trata de zonas del texto en donde prima un registro impersonal. En el segundo modo, el comentario, estaríamos más cerca de una prosa personal, en donde parecemos escuchar a alguien meditando, comentando e interpretando. Usando, por lo general, la primera persona, la línea de comentario funciona bajo la lógica digresiva y voluble de una prosa libre19: "pulverulenda que eu linho e desalinho que eu

\footnotetext{
${ }_{17}$ Algunos de ellos fueron publicados a fines de los 60 e inicio de los 70 en revistas como flor do mal, navilouca, código, qorpoestranho, circulando en lo que el autor llamó la "'marginália' dos anos 70". (CAMPOS, Haroldo de. Galáxias. São Paulo: Editora Ex Libris, 1984, s.p.). En 1976 Haroldo de Campos publicó una versión avanzada de Galáxias (reuniendo 43 textos) en su antología Xadrez de estrelas. Precurso textual. 1949-1974.

${ }^{18}$ CAMPOS, Haroldo de. "pulverulenda". In: Galáxias. São Paulo: Editora Ex Libris, 1984, s. p.

${ }^{19}$ Este término fue propuesto originalmente por Northrop Frye para describir un tipo especial de prosa, de ritmo asociativo, influenciada por la oración (unidad básica de la prosa convencional), pero cuya unidad rítmica sería, en definitiva, la frase. Esta unidad breve le permitiría a la prosa libre un movimiento más espontáneo, voluble y digresivo que el de la prosa expositiva basada en la oración. Cf. FRYE, Northrop. The Well-Tempered critic. Bloomington: Indiana University Press,
} 
cardo e descarto e descardo e carto e corto e discordo e outra vez recarto recorto reparto". En esta prosa libre, seguimos los movimientos de una mente ágil, que se mueve entre el ritmo asociativo del intelecto y el de la ecolalia - i. e. un juego permanente de aliteraciones, anáforas, rimas y repeticiones. En el caso citado, sería difícil decidir si el locutor está más atento al contenido intelectual de su discurso, en el que comenta técnicas de composición e inventa neologismos metaliterarios como "pulverulenda", o al juego de aliteraciones que ritman su pensamiento. Un ritmo y otro, el ritmo asociativo del pensamiento y el de la ecolalia, van siempre entrelazados en la línea de comentario del locutor haroldiano, dando forma a su pensamiento ecolálico.

Habiendo presentado esta descripción de lo que consideramos el dinamismo formal básico de Galáxias, en lo que sigue dejaré en suspenso problemas ligados a la línea del comentario personal del locutor para centrarnos en problemas referidos a las texturas impersonales que hemos denominado concreciones. Esta estrategia de lectura, creo, nos permitirá acercarnos de modo más frontal al sentido de crisis que dinamiza la prosa de Galáxias. Para esto, analizando dos pasajes de sus textos tardíos, intentaré discutir lo que podría significar una caída o falencia del espíritu neorrealista, del impulso hacia el afuera prosaico, que inspiró el proyecto original de 1964.

Comencemos por releer con atención el pasaje del texto 30 [1967] ${ }^{20}$, citado arriba. Al inicio, el locutor llama nuestra atención para sus técnicas de trabajo: quiere que notemos que trabaja como un artista constructivista, usando técnicas de montaje y operaciones aleatorias. Quiere que entendamos el texto como un juego de cartas o bloques verbales que corta, recorta, baraja, reparte, descarta, combina, etc. En sentido estricto,

1963, pp. 81-93. La idea de una prosa libre ha sido retomada de modo productivo por Perloff para estudiar la nueva prosa de los años 60 y 70. Cf. PERLOFF, Marjorie. Poetics of indeterminacy. Rimbaud to Cage. Evanston: Northwestern University Press, 1999, pp. 39-44; pp. 316-18.

${ }^{20}$ Respecto a esta numeración de los textos de Galáxias, una breve aclaración. La obra se compone de 50 textos. El autor llamó al primero y al último "formantes", diferenciándolos de los 48 restantes por el uso de cursivas. En su concepción original, los 48 textos comunes, sin cursivas, serían presentados como hojas "sueltas" y "permutables", pudiendo ser leídos en cualquier orden. Cf. CAMPOS, Haroldo de. "dois dedos de prosa sobre uma nova prosa". In: Invenção, n. 4. São Paulo: Obelisco, dez. 1964, p. 112. No obstante, en la edición definitiva (1984), el autor dispuso los textos en formato de libro, en una secuencia fija que responde exactamente al orden cronológico de escritura, indicando con precisión, en cada caso, la fecha de composición. Respetando la diferenciación entre formantes y textos comunes, y buscando enfatizar su carácter serial, he enumerado estos últimos según su orden de aparición en el conjunto definitivo: comenzando por el texto 2, que sigue al formante inicial, hasta el texto 49 , que antecede al formante final. En cada caso, indico entre paréntesis el año de composición. 
considero que las técnicas constructivistas a las que el locutor refiere aquí apuntan, no a los principios formales que rigen su línea de comentario personal (que definimos como un pensamiento ecolálico en prosa libre), sino a la forma del tipo de texturas impersonales que hemos llamado concreciones. Nos introducimos en tales texturas cuando, en lugar de la dicción del locutor, que realizará una desaparición elocutoria, nos vemos frente a una yuxtaposición de frases readymade en diversos idiomas que anticipan la estructura quebradiza y paratáctica de la secuencia que nos interesa comentar. Sus materiales son heterogéneos: una frase enigmática ("pena que ela seja uma ptyx"), una pared callejera con imágenes pornográficas, impresiones provenientes de un café, las mujeres monocromáticas de Yves Klein estampándose sobre una tela en blanco. La forma de este tipo de texturas es, a mi juicio, heredera del cubismo literario de Ezra Pound: una yuxtaposición de bloques verbales con contornos fuertes, que presentan imágenes condensadas provenientes de contextos heterogéneos. Al ser apilados, uno tras otro, estos bloques impersonales forman constelaciones multilaterales y simultaneístas que debemos procesar en una lógica ajena o contrapuesta a la de una sintaxis discursivolineal. ${ }^{21}$

La frase "pena que ela seja uma ptyx" y sus retornos merecen un comentario detenido. Esta frase remite al célebre "Soneto en yx" [1899] de Stéphane Mallarmé, un soneto emblemático para la abstracción literaria, en la medida en que presentó una poética radical que afirmaba las cualidades intrínsecas del medio verbal por sobre cualquier subordinación a convenciones y sentidos vigentes en el espacio extra-artístico. En su busca formalista de improbables rimas en yx, Mallarmé inventó la palabraenigma "ptyx", sin significado alguno fuera del mundo del poema. "Ptyx" contaría como uno de los primeros emblemas literarios de la abstracción artística: una afirmación orgullosa, soberbia, de la primacía y autonomía de la poesía, y de su medio específico. Haroldo, que conocía muy bien la poética de Mallarmé, no recuperó tal emblema de la abstracción y de la

\footnotetext{
${ }^{21}$ En este sentido, considero que, para leer Galáxias, es recomendable familiarizarse con la versión poundiana de cubismo literario, sea en términos de vorticismo o de método ideográmico. Haroldo de Campos estudió a fondo estos métodos desde la década de 50. Su interés tal vez se haya intensificado durante el período de escritura de Galáxias. A mi juicio, el cubismo literario que practica en esta obra es de linaje poundiano. (Si tuviese que tomar posición en las batallas del paideuma concreto, en relación a Galáxias, apuntaría a Pound, y especialmente a sus "Pisan Cantos"). El hecho de que, en 1977, el autor haya publicado Ideograma. Lógica, Poesia, Linguagem, un libro que evidencia el nivel de compenetración con estos métodos, y con sus presupuestos, refuerza esta hipótesis. Para una notable síntesis del cubismo literario de Pound, entendido como bloques verbales o imágenes en relación, ver POUND, Ezra. Gaudier-Brzeska. A memoir. Nova Iorque: New Directions Books, 1970, pp. 81-94. Para un comentario más detenido y sistemático, ver KENNER, Hugh. The poetry of Ezra Pound. [1951] Lincoln. University of Nebraska Press, 1985. Este último fue un libro de cabecera para Haroldo de Campos, citándolo con frecuencia desde los tiempos del concretismo poético de los 50 .
} 
poesía pura por acaso. ¿Cómo interpretar, entonces, que haya realizado este gesto de fidelidad a la abstracción literaria al interior de un proyecto neofigurativo y prosaico? ¿Sería viable conservar actitudes propias de la abstracción mallarmeana en una prosa orientada a dejar entrar, de modo masivo, el afuera prosaico?

Al respecto, la posición del autor parece ser ambivalente. Comencemos por notar que, en Galáxias, "ptyx", símbolo de la pureza poética, será conectado con "puta", símbolo de la perdición prosaica. Esta conexión es primero insinuada, y lamentada, en la primera oración: "pena que ela seja uma ptyx". Será confirmada de modo abrupto al ser yuxtapuesa a "she's a whore". Nuestra oración reaparecerá más adelante, de modo compulsivo y recortado, en "pena que ela seja/ a cadeira sacudida de riso espernava grossas coxas de nylon". Aquí un montaje interrumpe el predicado esperado ("uma ptyx" / "a whore"). Pero no lo anula. Siendo un predicado simbólicamente cargado de enigma y erotismo, probablemente quedará resonando en la memoria del lector, que verá como otro bloque de prosa, terminado en "grossas coxas de nylon", lo substituye súbitamente, como si fuese una rima en yx. Pero aquí no hay rima sonora. ${ }^{22}$ Más bien, estaríamos frente a algo del orden de un pattern: la sensación de que algo en la forma se repite, pero sin que podamos definir fácilmente de qué se trata. ${ }^{23}$

Nuestro pasaje parece sugerir que, en el afuera prosaico de Galáxias, las rimas de la poesía pura (abstracta) pueden ser redefinidas como patterns de estímulos sexy que encontramos en todo lugar. Recurrencias que parecemos encontrar al acaso. Cierto tipo de repetición que se expresaría, por ejemplo, en la contingencia prosaica de unas piernas vistas en un café. Pero también en las mujeres monocromáticas de Yves Klein marcando una tela en blanco. ¿Sería una pena que, en este proyecto prosaico, "ptyx", símbolo de la poesía pura, pasase a funcionar como una "puta"? Esta posible degradación de actitudes abstractas y puristas reorientadas hacia el afuera ha sido insinuada aquí y en otros textos de la obra. No obstante, la estrategia de Haroldo será precisamente aproximarse en $y x$ hacia la vida cotidiana: con la concentración de un artista abstracto que busca y

\footnotetext{
${ }^{22}$ Notemos, de todos modos, que este bloque verbal ("grossas coxas de nylon") contiene las letras relevantes de la rima (yx), aunque en orden invertido (xy). Si no se tratase de Haroldo, asumiría que esto no ha sido voluntario.

${ }^{23}$ Respecto al término pattern, en su Gaudier-Brzeska, Pound nos ofrece una definición magistralmente simple y general de un concepto complejo: "por 'pattern' quieres decir algo con una 'repetición' dentro". (POUND, Ezra. Op.cit., p. 87, traducción mía). Cita original: “by 'pattern' you mean something with a 'repeat' in it". La fuerza de esta definición está en su soltura, en su capacidad de indicar el carácter vago de aquello que se repite: no especifica qué se repite ni cuál sería su vehículo específico: puede ser una imagen, un sonido, una asociación, una combinación, una insinuación. Siguiendo esta pista, al hablar de patterns en Galáxias refiero básicamente a aquellas imágenes o bloques de palabras en los que percibimos, aunque sea de modo vago, una repetición - algo ya visto, ya sentido.
} 
presenta, obsesivamente, intensidades, simetrías y repeticiones. Pues, pensándolo en sentido inverso, ¿no sería posible que lo prostibularprosaico se transfigurase en "ptyx"? Como mencionamos al inicio, retrospectivamente el autor consideró que, en Galáxias, una "insinuación épica" se resolvió en una "epifánica". En pasajes como el que leímos, ¿estaríamos frente a epifanías prosaicas? No parece un término ajustado para una prosa que revela cierta estructura compulsiva de la vida cotidiana. Prefiero leer su declaración retrospectiva como una indicación de que, en Galáxias, algo en el tratamiento del material prosaico no habría llegado a buen término. Algo se traba, se torna estático y repetitivo.

Antes de expandirnos en conclusiones, introduzcámonos en nuestra segunda y última concreción. Corresponde al texto 35 [1968]:

o se tiene la chispa o no se tiene citava galdós e parecia saído de um disparate de goya abrefechava aspas com dedos-cornos à altura da testa e talhe de louva-deus um louva-deus marron vestindo charpas de barata a garota sentada no colo de lincoln da estátua de distribuía panfletos contra a guerra o professor abraspas citava galdós fechaspas charpas de barata pernas longas róseas no colo da estátua e depois se soube do velho embaixador que dormia com bifes no rosto chuletas bistecas para manter a pele lisa a estátua distribuía panfletos da moça rosipêndula molhado por este caleidoscópio eles dizem teleidoscope você vira também objeto do jogo uma rosa de braços se abre entre vidros e mãos cabeças simetrizam um leque de arestas e este quadro na parede se despenha num abismo de duplos vertiginosos quem não viu a mulata narcisa remoinhando o umbigo op no olho leitoso da tv ou então são paredes e lustres que correm para uma rosácea de brilhos com metais e vasos de flores onde sapatos de camurça verde formam lagartas de borboletas sem asas ${ }^{24}$

Frente a esta textura cubista pesada, formada principalmente por micronarrativas e imágenes condensadas, tal vez lo primero que impresione al lector sea la extrema arbitrariedad o aleatoriedad del material. Pues, ¿qué relación sustantiva podría establecerse entre un académico grotesco, una joven que reparte panfletos anti-Vietnam en Washington, la anécdota de un embajador con bistecs en la cara, una mulata sensual en la tv, cuadros que caen, rosáceas paradisíacas con flores, zapatos de gamuza y larvas de mariposa? En principio, ninguna. Este

${ }^{24}$ CAMPOS, Haroldo de. "principiava a encadear-se um epos". In: Galáxias. São Paulo: Editora Ex Libris, 1984, s.p. 
pasaje no sería más que el resultado de la aplicación técnica y cruda, a la John Cage, de operaciones aleatorias. Difícil negar que un efecto de aleatorismo bruto, informalista y caótico, sea aquí una primera capa de sentido. El propio locutor ficcional ha advertido al lector, en más de una ocasión, que usa operaciones aleatorias. Por otra parte, sabemos que nuestro autor, durante los 60, siguiendo a Umberto Eco y a Pierre Boulez, manifestó su fascinación por versiones fuertes de incorporación del acaso a la obra, siempre y cuando supervisadas por una inteligencia constructivista. ${ }^{25}$

En materias de aleatorismo, el locutor haroldiano nos revela, desde el inicio de Galáxias, que ha optado por una estrategia paradojal. En el primer formante [1963] afirma su intención de componer un libro "onde tudo seja fortuito e forçoso". ${ }^{26}$ Es decir, máxima arbitrariedad y máxima necesidad. ${ }^{27} \mathrm{Y}$, de hecho, pese a la arbitrariedad innegable que atraviesa el pasaje citado, percibimos cierta mediación general. Perloff, comentando otro texto de Galáxias, afirmó que el autor buscaría presentar "no el evento en sí mismo sino la respuesta mediada y la regurgitación de ese evento". ${ }^{28}$ Este comentario apunta hacia aspectos poco evidentes de la forma. Aquello que aparece o es presentado como evento crudo sería, visto con atención, una regurgitación, es decir, algo que retornaría ya mediado por algún tipo de experiencia o proceso no exactamente orgánico. Breves segmentos narrativos, por ejemplo, los referidos al profesor que cita a Galdós o a la joven que reparte panfletos, son descompuestos en gestos y pedazos estimulantes (las piernas rosa de la joven, el regazo de la estatua, las manos y cabeza del profesor) que retornan de modo compulsivo y condensado, desconfigurando la sintaxis de la prosa. La sintaxis de una oración puede aparecer formalmente desconfigurada, como en "a garota sentada no colo de lincoln da estátua de distribuía panfletos contra a guerra". ${ }^{29} \mathrm{O}$ semánticamente desconfigurada, como en "a estátua distribuía panfletos da moça rosipêndula", en donde la estatua sustituye a la joven en la

\footnotetext{
${ }^{25}$ Cf. CAMPOS, Haroldo de. "A arte no horizonte do provável" [1963]. In: A arte no horizonte do provável e outros ensaios. São Paulo: Perspectiva, 2010.

${ }^{26}$ CAMPOS, Haroldo de. "e começo aqui". In: Galáxias. São Paulo: Editora Ex Libris, 1984, s.p.

27 Considero que este principio expresa una orientación diametralmente opuesta a la poética abierta de John Cage. Para el estadounidense, aprender a concebir lo fortuito simplemente como fortuito, dejando caer ansiedades de control integral, apuntaría en una dirección liberadora, abriendo nuevos caminos para el arte. Cf. CAGE, John. "Experimental music". In: Silence. Lectures and writings [1961]. Londres: Marion Boyars Publishers, 1995. En Galáxias, Haroldo de Campos propuso una versión muy diferente de la incorporación del acaso, en donde máxima aleatoriedad sería, de algún modo, compatible con máximo control formal.

${ }^{28}$ PERLOFF, Marjorie. "Refiguring the Poundian Ideogram: From Blanco/Branco to the Galáxias". In: <http://marjorieperloff.com/essays/refiguring-pound/>, s.p., vistado en 28 Septiembre 2018, traducción mía. En este escrito, Perloff analiza el texto 8 [1964], "isto não é um livro". Cita original: "Not the event itself but the mediated response and regurgitation of that event"

${ }^{29}$ Reformulando la frase en prosa convencional tendríamos: "a garota sentada no colo da estátua de lincoln distribuía..."
} 
posición de agente. La forma de esta prosa sufre accidentes y desconfiguraciones bajo la presión de estas unidades estimulantes. Como resultado estético podemos comenzar a sentir que, en cualquier momento, pedazos estimulantes de materiales prosaicos pueden retornar con un peso gravitacional propio, de ritmo enigmático, casi aleatorio. De algún modo, entendemos que lo que interesa aquí es seguir la pista, el ritmo o movimiento enrarecido de estas unidades sueltas capaces de minar severamente las formas convencionales de la prosa.

De modo que nuestro pasaje no sólo produciría un efecto de aleatorismo crudo, de intensa inorganicidad, sino, al mismo tiempo, puede producir una sensación generalizada de recurrencia o déjà vu. Se torna difícil distinguir entre evento y regurgitación, entre lo que aparecería por primera vez y lo que retorna mediado por cierto tipo de memoria. Esta nueva prosa, en lugar de ser un receptáculo de eventos, sería el resultado de alguna modalidad de recolección compulsiva de material prosaico, de carácter colectivo-anónimo, y orientado a lo estimulante. Notemos que, para revelarse en la forma literaria, esta modalidad de memoria o recolección requiere técnicas y principios propios de la abstracción geométrica o constructivista: montaje de bloques verbales, contornos duros, multilateralismo, operaciones aleatorias. Pero, a diferencia del movimiento abstracto de los 50, aquí este repertorio estaría al servicio de representar, figurar o apuntar hacia aspectos de la vida cotidiana. Como vimos al inicio de este escrito, Greenberg ya había percibido, en su versión de lo semi-abstracto, un desvío neorrealista de principios asociados a la abstracción artística: "todo aquello que usualmente sirve a lo abstracto y a lo decorativo - planaridad, meros contornos, diseño multilateral o simétrico - es puesto al servicio de la representación" ${ }^{30}$ Creo que en los dos pasajes analizados hemos podido notar este tipo de desvíos.

Una lectura atenta de estas texturas concretistas revela una infraestructura de repeticiones compulsivas que cohesiona vagamente materiales prosaicos que, vistos desde otro ángulo, parecerían perfectamente arbitrarios y aleatorios. Retornos de piernas, manos y regazos de estatua, pueden ser combinados al baile de una mulata en la tv, todos participando de una lógica general de "duplos vertiginosos num caleidoscopio". Desde esta perspectiva, en su impulso de apuntar hacia la infraestructura de una vida cotidiana espectacularizada y compulsiva, las concreciones del escritor paulista podrían ser aproximadas a versiones

\footnotetext{
30 GREENBERG, Clement. Op.cit., p. 127. Sin embargo, no olvidemos que la elaboración de lo semi-abstracto en Greenberg apunta a la paradoja. Pues, por su vez, la figuración y la ilusión puede ser puestas al servicio de la abstracción. Creo que este doble juego, paradojal, está en el centro de la dinámica formal de Galáxias.
} 
traumáticas del pop como la de Andy Warhol. ${ }^{31} \mathrm{O}$ bien, a la elaborada por William Burroughs en la prosa de su Cut-up Trilogy (1961-68), en la que experimentaba, a la par de Haroldo, con técnicas de montaje y operaciones aleatorias capaces de revelar nuevas dimensiones inorgánicas de la memoria y experiencia cotidiana de los 60 .

Sin embargo, no todo en las concreciones de Galáxias apunta hacia un cotidiano hipermoderno. Ni todo en la forma responde a la mente de un artista abstracto de linaje constructivista. En esta obra nos enfrentamos, asimismo, al estilo de un alegorista, con un gusto voluntario por la oscuridad, por el simbolismo y por alcanzar momentos extáticos de visión. Es a una mente de alegorista que atribuyo la imagen densa y difícil con la que se cierra nuestro pasaje: una rosácea de luces, metales, vasos de flores, zapatos de gamuza que se transfiguran en larvas de mariposas sin alas. Esta imagen compleja y paradójica, a la vez rosácea paradisíaca y naturaleza muerta, funciona como un vórtice que absorbe los bloques y pedazos del texto. ¿Sería esta rosácea el lugar en donde el movimiento vertiginoso de las imágenes estimulantes del afuera llegaría a su parálisis? ¿Se cifra y se conserva aquí, en estado larvario, o muerto, el material prosaico que había insinuado la posibilidad de un epos, de un "novo realismo"? Si tal fuese el mensaje encriptado por el alegorista, sería una visión oscura. Entonces, ¿por qué presentar este material abortivo al interior de una rosácea luminosa, emblema dantesco de la visión paradisíaca?

En definitiva, el cubismo literario que Haroldo despliega en estas concreciones es desconcertante Constelaciones en prosa que combinan aleatorismo crudo, mentalidad alegórica y mediación generalizada por la vía de patterns enigmáticos. Máxima arbitrariedad y máxima necesidad. A nivel de experiencia estética, con su condensación extrema y sus disonancias a nivel de sentido y principios formales, estas texturas sobrecargan la mente. Suelen dejarnos aturdidos y perplejos. Pues parecen

\footnotetext{
${ }^{31}$ Refiero aquí al notable análisis de la infraestructura traumática del pop de Warhol realizada por Hal Foster, apoyándose en la lógica de la acción diferida de Jacques Lacan: "'Lo que es repetido', escribe Lacan, 'es siempre algo que ocurre . . . como por acaso' (...) Así ocurre con estos pops: parecen accidentales, pero también parecen repetitivos, automáticos, incluso tecnológicos (la relación entre accidente y tecnología, crucial para el discurso del shock, es un gran asunto warholiano)". (FOSTER, Hal. The return of the real. The avant-garde at the return of the century. Cambridge: The MIT Press, 1996, p. 134, cursivas mías, traducción mía). Al mostrar que en el pop de Warhol aleatoriedad y repetición compulsiva mantendrían una conexión subterránea, la lectura de Foster complementa nuestra discusión sobre patterns y compulsiones en Galáxias. Los pedazos y unidades estimulantes que retornan compulsivamente, produciendo accidentes y desconfiguraciones en la sintaxis de esta nueva prosa, corresponderían a los pops teorizados por Foster. Cita original: "What is repeated', Lacan writers, 'is always something that occurs... as if by chance' (...). So it is with these pops: they seem accidental, but they also appear repetitive, automatic, even technological (the relation between accident and technology, crucial to the discourse of shock, is a great Warhol subject)".
} 
querer decir demasiadas cosas al mismo tiempo. El efecto es de estridencia: un tipo de experiencia estética que no parece posible sostener por mucho tiempo. Y, dado que concreciones como las que hemos leído aparecen una y otra vez a lo largo de la obra, tal perplejidad y sensación de crisis se torna un estado permanente.

La experiencia de incomodidad que estas texturas estridentes pueden provocar es un problema para el lector y para el locutor. Al respecto, considero que el texto 35 [1968] marca un punto de inflexión mayor en el trayecto de la nueva prosa de Haroldo de Campos. Será precisamente en este texto que el locutor ficcional reconocerá, por primera vez, la falencia de su proyecto épico, de aquella orientación fuerte hacia el afuera cotidiano que había dado sustento, en el proyecto original de 1964, a la idea de un posible "novo realismo". El texto 35 se abre con el siguiente comentario: "principiava a encadear-se um epos mas onde onde sinto-me tão absconso como aquela sombra (...) quantas máscaras até chegar ao papel quantas personae até chegar à nudez una do papel para a luta nua do branco frente ao branco". ${ }^{32}$ Esta declaración de falencia del impulso épico, del impulso exterior, es seguida por el anuncio de una reorientación programática del proyecto en términos de una "luta nua do branco frente ao branco". Considero que tal fórmula, la noción de un blanco frente a blanco, indica un giro en $180^{\circ}$ en relación a la orientación prosaica del proyecto original. El conjunto de los textos tardíos (1966-1976), sobre todo aquellos escritos después de 1968, ensayarán las posibilidades de este nuevo proyecto "branco frente ao branco". Analizar tales ensayos, que el texto 35 anuncia e inaugura, exigiría otro escrito. 33

En esta aproximación a los textos tardíos he intentado introducir al lector de modo frontal a lo que las concreciones pueden provocar. Tal estrategia implicó silenciar la línea de comentario del locutor ficcional, lo que, admito, es cuestionable. No obstante, esto nos ha permitido argumentar, sin mayores desvíos, que el contenido difícil de estas texturas impersonales estaría más cerca de la perplejidad, de la estridencia y de un malestar difuso, que de paraísos, epifanías y éxtasis - que es el tipo de imágenes más cercano al registro del locutor haroldiano y a la de una parte de la fortuna crítica de Galáxias. Considero que concreciones como las que hemos leído, que proliferan por toda la obra, provocan un sentido de crisis.

\footnotetext{
${ }^{32}$ CAMPOS, Haroldo de. "principava a encadear-se um epos". In: Galáxias. São Paulo: Editora Ex Libris, 1984, s.p.

${ }^{33}$ Para una interpretación reciente de esta fase tardía de Galáxias ver AGUILAR, Gonzalo. "Parte III. A vereda para o branco". In: Idem. Hélio Oiticica, a asa branca do êxtase. Arte brasileira 1964-1980. Rio de Janeiro: Anfiteatro, 2015.
} 
En caso de que hayamos logrado dar sustento formal a esta idea, creo que este ensayo habrá logrado un objetivo importante.

A modo de cierre, y reincorporando ahora la figura del locutor ficcional a nuestra reflexión, estamos en condiciones de formular una pregunta relevante sobre la forma general de Galáxias: ¿qué función tendría este sentido de crisis en la forma global de los textos y de la obra? A nuestro juicio, la prosa semi-abstracta de Haroldo de Campos no sería una forma de la resolución (llámese epifánica o paradisíaca) sino una forma de la perplejidad, de lo que no cuadra, de lo que incomoda. Galáxias pone en escena los esfuerzos y astucias que un sujeto realiza para procesar e interpretar estos descuadres, ensayando modos de situarse y orientarse en contextos inorgánicos e inestables. El protagonista o histrión de tales movimientos e interpretaciones es el locutor ficcional, una especie de Virgilio que media y orienta la relación del lector con la forma intrincada de estas nuevas texturas.

Galáxias sería una obra que, a través de un contrapunto reflexivo entre concreción impersonal y comentario personalista, dramatiza o teatraliza el procesamiento de una crisis de difícil definición, que toca nervios sensibles de una comunidad. No sólo por referir a aspectos enigmáticos de una vida prosaica o común, sino también, y quizás principalmente, por usar de modo intensivo técnicas y presupuestos de un movimiento estético, la abstracción geométrica, que en el Brasil del período pos-1945 fue portador de grandes ilusiones colectivas respecto a la forma que adoptaría la modernidad industrial en el país. Que, a partir de 1964, el uso intensivo de técnicas y principios constructivo-geométricos comenzase a producir ansiedades y perplejidades en lugar de satisfacciones y convicciones; a cristalizar un sentido de lo amorfo y de lo estridente, en lugar de un sentido de orden y planificación, no debe haber sido algo fácil de procesar, o de admitir, para este colectivo histórico.

Así, el sentido de crisis que las concreciones provocan respondería no sólo a aquello que revelan del afuera cotidiano común, en una llave neofigurativa; respondería, asimismo, al cambio subterráneo de función y valencia que sufrieron las técnicas y principios constructivistas durante el largo período de escritura de Galáxias (1963-1976). En otras palabras, para aproximarnos a su sentido de crisis, no basta un marco neorrealista, sino que, adicionalmente, debemos considerar, con perspectiva histórica, el peso simbólico y el destino de su base abstraccionista. Las concreciones de Galáxias serían, bajo esta hipótesis, formas ruinosas del movimiento abstracto brasilero. Y como tales, se tornan una incomodidad común para el locutor y para el lector; como si nos hablasen, oblicuamente, de un proyecto colectivo que falló y, cuyo estado actual, parece exigir un ejercicio proliferante de reflexiones, ajustes y reformulaciones, realizados en estado de perplejidad. 
En este escrito he intentado establecer una base para leer una forma general, de carácter contrapuntístico, que ensaya ajustes entre un sujeto con pretensiones de liderazgo colectivo y una situación inorgánica. Una forma en donde la inorganicidad se ha tornado presupuesto y motor de una actividad simbólica incansable que, por su vez, debiese ser evaluada críticamente por el lector. Pues el lector también entra en el juego global de la forma. Las concreciones nos sitúan, como lectores, en una posición incómoda que nos fuerza a buscar salidas, distancias y perspectivas. Pues, si no queremos permanecer aturdidos, debemos tomar distancia: revisar, medir, examinar, comparar, meditar. Y luego volver a confrontar estas formas. Es a la posibilidad de establecer una posición más autónoma o escéptica para el lector de Galáxias, una que permita calificar los movimientos simbólicos y las visiones extáticas del locutor ficcional como un momento parcial dentro del juego global de la forma, que he dedicado este escrito. Desde este ángulo, el tipo de texturas cubistas que hemos leído pasarían a funcionar como un extraño e inestable principio de objetividad contra el cual los movimientos veloces del locutor haroldiano pueden ser medidos y evaluados.

Para cerrar el círculo, vuelvo a problemas de concepción. No quisiera defender que Galáxias procese de modo satisfactorio el sentido de crisis que su forma produce, pues creo que no lo consigue. Mi defensa de la obra se sitúa, más bien, a nivel de concepción. En momentos históricos de crisis, marcados por una transformación subterránea de presupuestos colectivos básicos, concebir una nueva forma o modo simbólico capaz de procesar tales movimientos puede tener mayor urgencia que lograr buena factura en modos que han perdido la capacidad de tocar los nervios de una comunidad. Creo que la prosa semi-abstracta de Galáxias, con sus altos y bajos, acierta en términos de los problemas de forma que ayudó a definir a partir de los 60 y 70. Responde, en el nivel profundo de sus presupuestos formales, a la pregunta por su hora histórica. Al respecto, me gustaría finalizar retomando una pregunta con la que Roberto Schwarz intentó formular la incomodidad colectiva que inauguraría el período contemporáneo en Brasil. ( $\mathrm{Y}$ que me parece válida para muchos otros países de la región). Es la siguiente: "E se a parte da modernização que nos tocou for esta mesma dissoçiação agora em curso, fora e dentro de nós? E quem somos nós nesse processo?". ${ }^{34}$ Esta pregunta define una situación inorgánica (externa e interna), un malestar colectivo y un problema de perspectiva y de ajustes autorreflexivos. Creo que, más allá de las respuestas específicas, muchas veces insatisfactorias, que Haroldo de Campos haya ofrecido en Galáxias, esta pregunta está muy cerca del núcleo

\footnotetext{
34 SCHWARZ, Roberto. "Fim de século". In: Sequências brasileiras. Ensaios. São Paulo: Companhia das letras, 2014, p. 198, cursivas del autor.
} 
que dinamiza la forma de su prosa semi-abstracta. En tal sentido, estaríamos frente a un modo simbólico que merece atención.

Jorge Manzi Cembrano é chileno e possui doutorado em Teoria Literária e Literatura Comparada pela Universidade de São Paulo, tendo sido orientado pelo Prof. Dr. Jorge de Almeida. Defendeu recentemente o grau de doutor com a tese Abstração e Informalismo depois de 1945: de Pedrosa e Greenberg à Nova Prosa de Haroldo de Campos (2019), um estudo comparado sobre a ascensão e crise do movimento da arte abstrata no Brasil e nos Estados Unidos durante o período pós-1945. $\mathrm{Na}$ tese, a prosa literária de Haroldo de Campos teve um lugar de destaque. Contato: jamanzi@usp.br 